\title{
Diagnostics of the condition of sucker-rod pumping units after the analysis of dynamogram cards
}

\author{
Georgy Milovzorov ${ }^{1}$, Aleksei Ilyin, ${ }^{2, *}$, and Pavel Shirobokov ${ }^{2}$ \\ ${ }^{1}$ Sarapul Polytechnic Institute, Kalashnikov Izhevsk State Technical University (branch), 427960, \\ Sarapul, Russia \\ ${ }^{2}$ Kalashnikov Izhevsk State Technical University, 426069, Izhevsk, Russia
}

\begin{abstract}
Despite of the increased share of oil wells equipped with submersible electrical centrifugal pumps, a considerable part of them is equipped and operated with sucker-rod pumping units. When operating wells with sucker-rod pumping units, different plunger pumps are used. The rod string is operated in severe environment due to long contact with highly corrosive well products and time-variant loads. Taking into account all acting loads, the diagnostics of the condition of sucker-rod pumping units is a difficult task. At the majority of oil fields in Russia, the operation of wells equipped with sucker-rod pumping units is controlled by portable and stationary dynamographs of various models. Moreover, dynamographs are used, as a rule, only to obtain images of dependence of the force on the polished piston rod upon its stroke. Based on dynamograms it is possible to find the well flow rate, pump capacity, force on the polished piston rod, etc. But one of the main problems to be solved with the help of dynamometry is the forecasting of down-hole equipment condition in the process of further operation. In this paper we overview the methods to diagnose the condition of sucker-rod pumping units based on dynamograms. The aim of the work is to develop the mathematical model to forecast the failures of down-hole pumping equipment on the results of dynamometry to automatize the control process of the unit operation. The research tasks are to analyze the existing methods for diagnosing the condition of sucker-rod pumping units, and to develop the mathematical model for forecasting the failure of the valve unit leakage. As a result, the method for forecasting the increased failure on the example of the fluid leakage in the pump injection unit is proposed. The permissible boundaries of the change in the relative force on the polished piston rod are drawn up. As a result, the failure increase is forecasted based on the frequency of the relative force on the polished piston rod getting within the interval obtained.
\end{abstract}

\footnotetext{
*Corresponding author: ilalp@inbox.ru
} 


\section{Introduction}

The following factors are usually pointed out among those for increasing oil extraction efficiency: application of rational systems for field development, improvement of drilling technology, wide introduction of modern methods for increasing reservoir recovery, application of advanced technological processes, as well as the extension of the interval between repairs of well operation. One of the urgent tasks is diminishing the failures of pumping equipment operation, the solution of which demands the development of modern forecasting methods with their further implementation in information-measurement control and management system of the pumping equipment operation being worked out.

Despite the increased share of oil wells equipped with submersible electrical centrifugal pumps (ECP), a considerable part of them is equipped and operated with sucker-rod pumping units (SRPU).

When operating wells with sucker-rod pumping units, different plunger pumps are used. At present, a large variety of plunger pumps has been produced, different not only in design but also in their application area under different operation conditions.

SRPU scheme is demonstrated in Figure 1. The equipment consists of two parts: surface and down-hole.

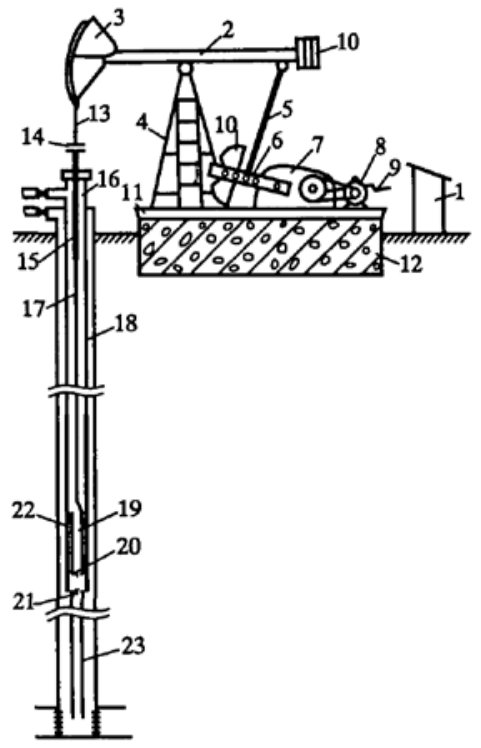

Fig. 1. SRPU schematic diagram:

1 - control station; 2 - walking beam; 3 - walking beam head; 4 - walking beam post; 5 - rocker arm; 6 - crank arm; 7 - gearbox; 8 - drive motor; 9 - brake; 10 - counterbalances; 11 - metal frame; 12 - concrete foundation; 13 - cable hanger; 14 - cross-beams; 15 - polished piston rod; 16 wellhead fittings; 17 - rod string; 18 - tubing string; 19 - pump plunger; 20 - injection valve; 21 suction valve; 22 - pump cylinder; 23 - linear

The pumping unit consisting of walking beam 2, walking beam head 3, walking beam post 4, rocker arm 5, crank arm 6, gearbox 7, drive motor 8, brake 9 and counterbalances 10 is the main element of surface equipment. A special control station 1 controls the surface equipment. The pumping unit, gearbox and drive motor are mounted on metal frame 11 fixed on concrete foundation 12. Walking beam head 3 has cable hanger 13 connected with polished piston rod 15 with the help of cross-beams 14. The wellhead is equipped with wellhead fittings 16 . The pumping unit is designed to take up loads acting in the point of rod hanging during the pumping cycle and transformation of the drive motor rotor rotary 
motion into the reciprocal motion of the walking beam head. Gearbox 7 is designed for decreasing the number of revolutions of drive motor 8 and increasing the torque on the output shaft, on which crank arms 6 are fixed.

The down-hole equipment comprises rod string 17 designed for transforming the reciprocal motion of the walking beam head to pump plunger 19, as well as for taking up the loads acting upon the rods during the pumping cycle. There is tubing string 18, on the bottom part of which pump cylinder 22 is fixed. The pump plunger has two injection valves 20, and the pump cylinder - suction valve 21 . Linear 23 is fixed to the pump suction.

As seen in Figure 1, when the walking beam head moves upwards, the plunger also goes upwards; at the same time, injection valve 20 closes under the action of the well products weight being in the tubing.

When the pressure in the pump cylinder goes down to the value smaller than the intake pressure (pressure in the well before the suction valve), suction valve 21 opens and the pump cylinder is filled with the well products (suction stroke). When the plunger moves downwards, the pressure in the cylinder goes up, the suction valve closes, and when the pressure in the pump cylinder (under the plunger) becomes higher than the pressure under the plunger, the injection valve opens and the products flow from the cylinder to the tubing string through the plunger (injection stroke). Then the cycle repeats [1].

It should be pointed out that the rod string is operated in harsh environment mainly not due to the extensive contact with the well products (they can be corrosive) but due to complicated and time-variable loads (tensile, compression, bending and torsional).

SRPU condition diagnostics, taking into account all acting loads, is a complicated physical task.

At the majority of oil fields in Russia the operation of wells equipped with SRPU is controlled by portable and stationary dynamographs of various models. Moreover, dynamographs are used, as a rule, only to obtain images of dependence of the force on the polished piston rod upon its stroke.

The range of tasks, for which dynamograms are used, is quite extensive: finding the well flow rate, down-hole pump capacity, force on the polished piston rod, etc. But one of the main problems to be solved with the help of dynamometry is the forecasting of downhole equipment condition in the process of further operation.

Thus, for more effective well operation and less failures in SRPU operation it is necessary to develop the technique for forecasting the down-hole equipment operation condition.

To solve this problem it is planned to work out the mathematical model for determining the dynamogram calculation parameters on the example of one type of failure for further use in the developed operation algorithm of information-measuring system (IMS) for automatic diagnostics and forecasting of SRPU failures.

The online processing of the dynamogram parameters and characteristics followed up by the online decision-making on the diagnostics results is one of the methods of effective control of SRPU operation.

The dynamogram allows revealing qualitative indexes of the deep-well pumping unit operation: passes through the injection and suction valves, gas influence, low and high plunger fit, plunger sticking, fluid leakage from pipes, etc. [2].

\section{Techniques for SRPU condition diagnostics}

The techniques for failure diagnostics can be divided into two classes [2 - 14]:

1) pattern recognition of practical dynamograms based on comparison with the reference; 
2) failure determination based on physical laws of obtaining the dynamogram of the pump abnormal operation.

The techniques of the second class do not allow, based on the failure features, providing the mathematical description. Therefore, it is difficult to use them in the algorithm of IMS operation.

The techniques of the first class comprise:

- matrix representation of the practical dynamogram;

- determination of the features of Fourier series from the practical dynamogram (AlievTer-Khachaturov technique);

- analysis of the deviation of practical dynamogram from the reference one (Grid Pattern technique);

- extraction of the relevant points on the practical dynamogram (Belov-Gilaev technique).

Nevertheless, along with the existing ones, the new forecasting techniques are based on a more detailed mathematical description of the forms of dynamograms with their further discrete transformation.

Modern investigations of foreign scientists in the field of SRPU diagnostics with the help of dynamograms are connected with the curve discrete transformation to reveal the shapes of dynamograms with their further processing. These can be the algorithms of position-binary identification of failures of deep-well pumping units or the algorithms of sparse multi-graph regularized extreme learning method (SMELM) applied as the failure classifier $[15,16]$.

These techniques, to various extents, solve the problems set up. But the following method for diagnosing SRPU operation condition is of certain interest.

The technique is proposed, in accordance with which the curves of upper and lower boundaries of relative force on the piston rod at some failure are plotted. The mathematical model for evaluating the failure increase for the most frequent cases of deviations in the deep-well equipment operation forms the basis of this method.

As an example, let us consider the forecasting of SRPU failure for the situation of fluid leakage in the pump injection unit.

The dynamograms of pump operation with fluid leakage in the injection unit (Figure 2) have the following characteristic geometry [2]:

\section{Dynamogram (period 1 of 3 )}

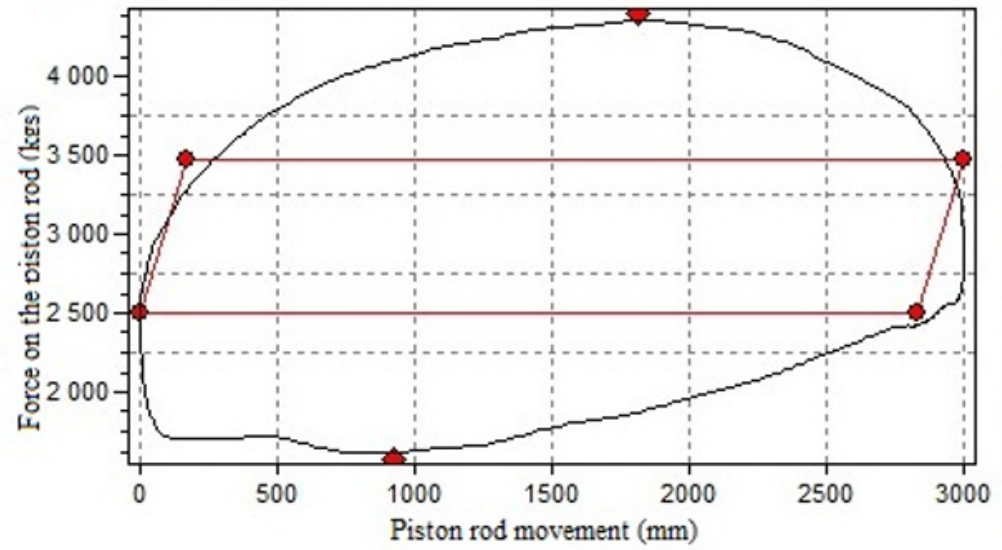

Fig. 2. Practical dynamogram of pump operation at fluid leakage in the injection unit 
- load bearing is described by the inclined curve different from the load bearing line during the normal pump operation by a smaller inclination angle;

- right upper angle of the dynamogram is rounded; the more is the leakage value, the more is the curvature radius of this rounding.

One of the reasons of such failure can be the increased content of heavy oil sediments (HOS), under which high-molecular compounds are understood (resins, asphaltenes, etc.) containing hydrocarbon, hydrogen, sulfur, nitrogen, and which possess high surface activity and complicate oil filtration in reservoirs [17].

The interval evaluation of the dynamogram characteristics is proposed based on the mathematical model of failure forecast.

Under the interval evaluation we understand the assessment, which is defined by two numbers - interval ends. With its help we can determine the accuracy and reliability of evaluations [18].

The essence of the interval evaluation is as follows. Let the statistic characteristic of dynamograms $\Theta^{*}$ found based on sampling method data serve as the assessment of the unknown parameter $\Theta$. Obviously, the more accurately the found characteristic $\Theta^{*}$ defines parameter $\Theta$, the less is the absolute value of the difference $\left|\Theta-\Theta^{*}\right|$. In other words, if $\delta>0$ and the following inequality is accomplished

$$
\left|\Theta-\Theta^{*}\right|<\delta
$$

then the less is $\delta$, the more accurate is the assessment. Thus, the positive number $\delta$ characterizes the evaluation accuracy.

However, statistic methods do not allow asseverating that assessment $\Theta^{*}$ satisfies the inequality (1). We can only speak about probability $\gamma$, with which this inequality is accomplished. Then, probability $\gamma$ is called the reliability (confidence probability) of the evaluation of $\Theta$ by $\Theta^{*}$, with which the inequality (1) is accomplished.

The definition of the confidence interval (2):

$$
\frac{\bar{x}_{\theta}-t_{\gamma} \cdot S}{\sqrt{n}}<x<\frac{\bar{x}_{\theta}+t_{\gamma} \cdot S}{\sqrt{n}}
$$

where $\bar{x}_{b}=\frac{\sum n_{i} x_{i}}{n}-$ average sampling, $S=\sqrt{\frac{\sum n_{i}\left(x-\bar{x}_{b}\right)^{2}}{n-1}}$ - mean square deviation of the corrected sampling dispersion, $t_{\nu}$ - tabular value of Student's coefficient, $n$ - sampling volume.

In Figure 3 the confidence interval for the case of fluid leakage in the injection unit during the SRPU plunger upwards motion and graphs of relative forces on the polished piston rod are given on the example of three wells with unpressurized injection units. 


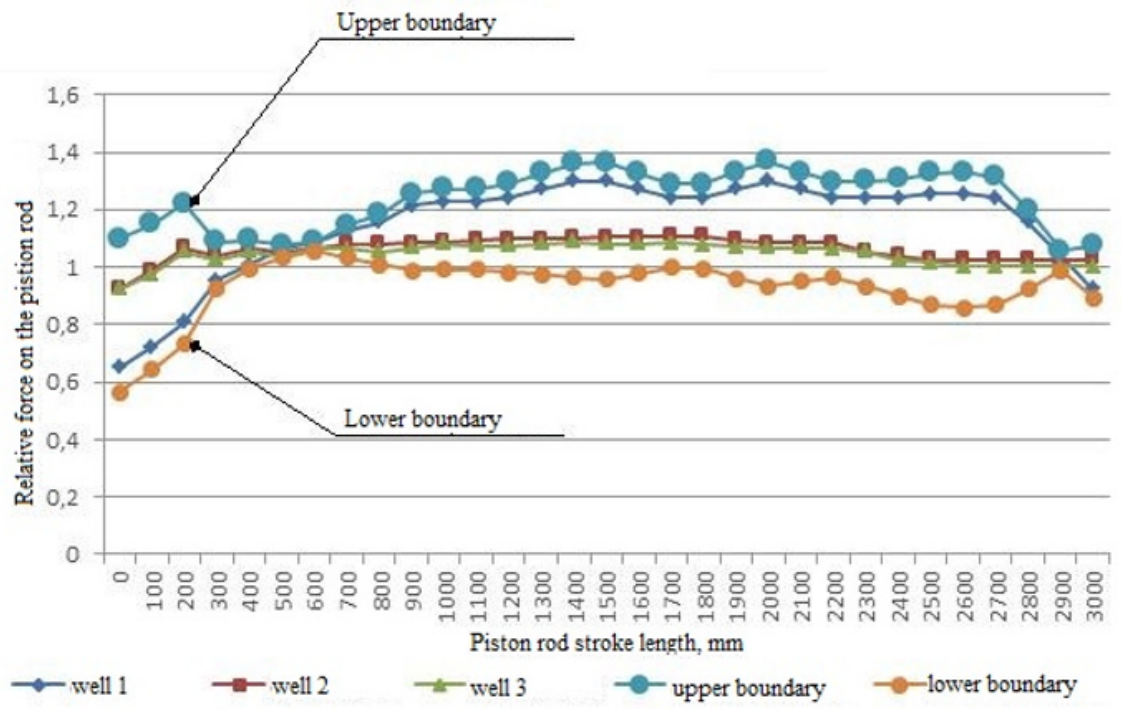

Fig. 3. The boundaries of confidence interval during the fluid leakage in the injection unit

As seen from this Figure, the graphs of relative forces of the wells are located between the upper and lower boundaries of the interval calculated. Consequently, if all the points of the relative force curve are within the specified interval, then, as follows from the analysis, this case is the failure.

\section{Research results and their discussion}

The changes in shapes of practical dynamograms of the equipment operation of one and the same well in different time periods are given as an example (Figure 4). At the normal operation of the deep-well pumping equipment, the following characteristic features described in [2] are appropriate for the dynamogram (Figure 4a):

- load bearing and relieving lines can be averaged by right lines;

- left lower and right upper angles are acute;

- inclination angles of load bearing and relieving lines equal the corresponding angles of theoretical dynamograms;

- load bearing line is parallel to the load relieving line.

For the pre-failure situation (Figure 4b) the inclination angles of the bearing and relieving lines of the practical dynamogram significantly differ from the lines of the simplest theoretical dynamogram. Besides, the right upper angle of the practical dynamogram is obtuse, thus, indicating the leakage in the pump injection unit.

The third dynamogram (Figure 4c) has smoothed curves of the practical dynamogram without vivid oscillations. The inclination angles of the bearing and relieving lines are not acute and significantly differ from the corresponding angles of the theoretical dynamogram. The dynamograms of such shape are characteristic for the case of fluid leakage in the injection unit. The more is the leakage, the more is the rounding radius of the right upper angle.

In Figure 4d the dynamogram of this well after the overhaul is demonstrated. The curve of the practical dynamogram has the main features appropriate for the dynamogram during the normal operation of the deep-well pumping unit listed in the case for Figure 4a. 


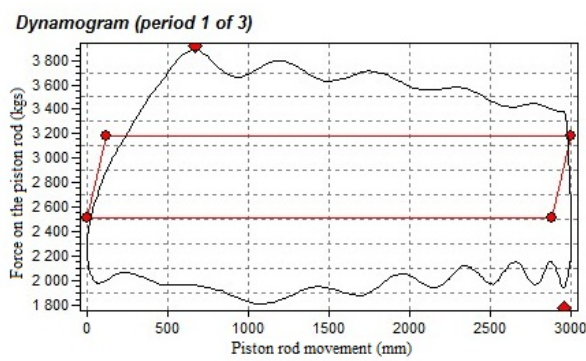

a) dynamogram of normal operation

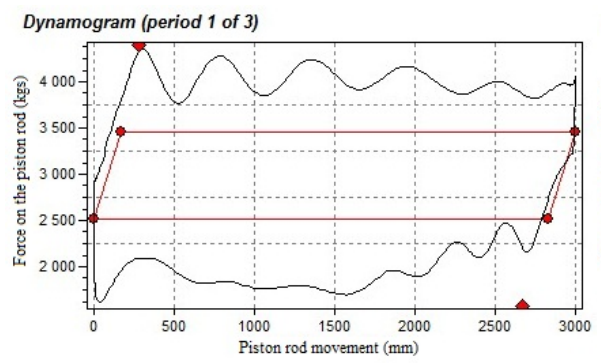

c) fluid leakage in the injection unit

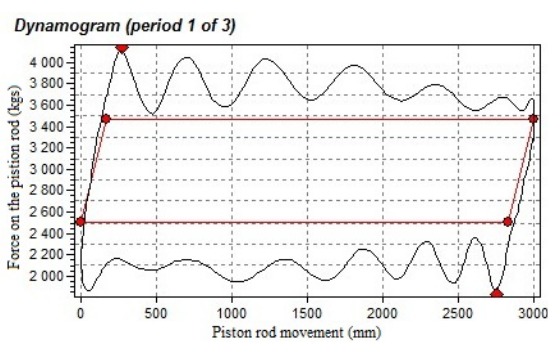

b) pre-failure situation

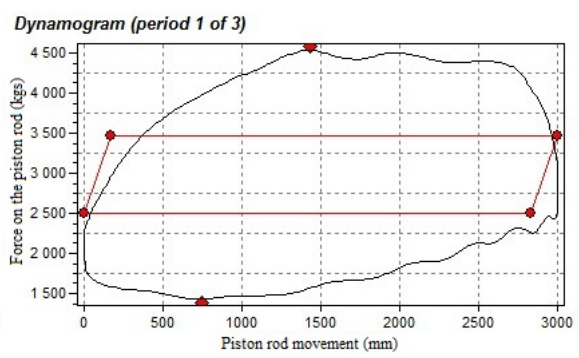

d) dynamogram after the well overhaul

Fig. 4. Typical dynamograms of SRPU operation

The graphs of relative forces on the polished piston rod during the plunger upward motion in SRPU have been plotted for these dynamograms (Figure 5); from the graphs it is seen that the more curve points get within the confidence interval, the more the equipment failure possibility increases. For comparison: during the normal operation of the pumping unit five points are outside the interval, and under the pre-failure condition - only two points. Thus, the failure increase can be forecasted.

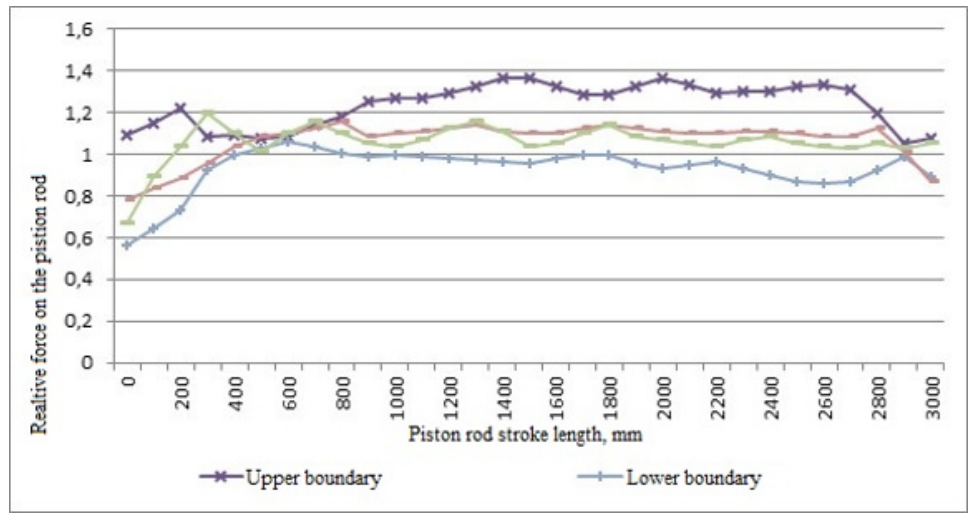

Fig. 5. To the boundaries of the confidence interval during the fluid leakage in the injection unit

Thus, the technique for SRPU condition diagnostics has been proposed. In accordance with this technique it is necessary to determine the upper and lower boundaries of the force on the piston rod under some failure. Since the calculated characteristics of dynamograms are processed, this allows diagnosing the deep-well pumping equipment condition based on the formal features of the dynamograms using numerical values.

The research results, when integrated with electrotechnical system [19], allow optimizing the pumping equipment operation to extend the deep-well pump service life and increasing the oil recovery factor of the productive reservoir. 


\section{Conclusions}

The existing techniques of SRPU failures diagnostics by domestic and foreign researchers have been analyzed. The mathematical model to forecast SRPU failures has been developed. The permissible boundaries of the change in the relative force on the polished piston rod have been plotted. As a result, the failure increase is forecasted based on the frequency of the relative force on the polished piston rod getting within the interval obtained. The modeling results allow algorthming the process of forecasting the failures increase of the deep-well pumping equipment, which makes it possible to be applied in the automation process of SRPU operation control.

\section{References}

1. I. T. Mishchenko, Well oil extraction: educational aid for HEIs. National University of Oil and Gas "Gubkin University” Publishers, 816 p. (2003)

2. G. G. Gilaev et al., Diagnostics of deep-well pumping wells by dynamometry. RA Paratsels Publishers, 212 p. (2008)

3. A. M. Zyuzev, A. V. Kostylev, System of sucker-rod pumping unit diagnostics based on neural network. Designing of scientific and engineering applications in MATLAB, proceedings of All-Russian scientific conference, IPU RAS, pp. 1266-1272 (2004)

4. R. Yu. Mansafov, New approach to SRPU operation diagnostics based on the dynamogram. Engineering practice, v. 9, pp. 82-89 (2010)

5. I. V. Dunaev, Diagnostics and control of sucker-rod pumping unit condition based on dynamometry and neural network technologies. Published summary of CSc dissertation: 05.13.06, 16 p. (2007)

6. S. V. Svetlakova, Information-measuring system of dynamometry of wells equipped with sucker-rod pumps: Published summary of CSc dissertation: 05.11.16, 16 p. (2008)

7. M. I. Hakimyanov et al., Comparative analysis of the capabilities of domestic and foreign automation systems of wells equipped with sucker-rod pumps. Petroleum engineering, v. 2, pp. 1-22 (2008)

8. V. D. Kovshov, M. E. Sidorov, S. V. Svetlakova, Dynamometry, modeling and diagnostics of sucker-rod pumping unit condition. Bulletin of HEIs, Oil and gas, v. 3, pp. 25-29 (2011)

9. T. A. Aliev et al., Algorithms of failure diagnostics in sucker-rod pumping units. Mechatronics, automation, control, v. 16(5), pp. 314-320 (2015)

10. Ao Zhang, Xianwen Gao, Fault diagnosis of sucker-rod pumping systems based on Curvelet Transform and sparse multi-graph regularized extreme learning machine. International journal of computational intelligence systems, v. 11, pp. 428-437 (2018)

11. B. M. Suchkov, Brief oil-field reference-book, research center "Regular and chaotic dynamics”, Institute of computer research, 400 p. (2008)

12. V. E. Gmurman. Probability theory and mathematical statistics: educational aid for HEIs, $9^{\text {th }}$ edition, Vysshaya Shkola Publishers, 479 p. (2003)

13. A. A. Lobaty et al., Mathematical modeling of hybrid electrotechnical systems. Science and engineering, v. 15(4), pp. 322-328 (2016) 